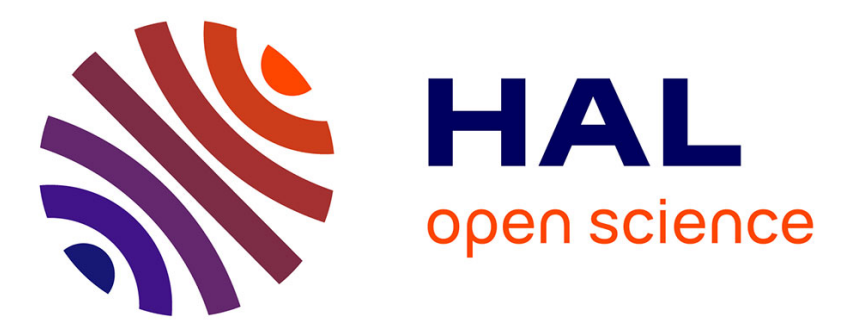

\title{
A new strontium bromide MOF composite with improved performance for solar energy storage application
}

Pierre d'Ans, Emilie Courbon, Anastasia Permyakova, Farid Nouar, Corine Simonnet-Jegat, Flavien Bourdreux, Loic Malet, Serre Christian, Marc Frere, Nathalie Steunou

\section{To cite this version:}

Pierre d'Ans, Emilie Courbon, Anastasia Permyakova, Farid Nouar, Corine Simonnet-Jegat, et al.. A new strontium bromide MOF composite with improved performance for solar energy storage application. Journal of Energy Storage, 2019, 25, pp.100881. 10.1016/j.est.2019.100881 . hal-03114368

\author{
HAL Id: hal-03114368 \\ https://hal.science/hal-03114368
}

Submitted on 18 Jan 2021

HAL is a multi-disciplinary open access archive for the deposit and dissemination of scientific research documents, whether they are published or not. The documents may come from teaching and research institutions in France or abroad, or from public or private research centers.
L'archive ouverte pluridisciplinaire HAL, est destinée au dépôt et à la diffusion de documents scientifiques de niveau recherche, publiés ou non, émanant des établissements d'enseignement et de recherche français ou étrangers, des laboratoires publics ou privés. 


\title{
A New Strontium Bromide MOF Composite with Improved Performance for Solar ENERGY STORAGE APPLICATION
}

Pierre D'Ans, ${ }^{\mathrm{a}, \mathrm{b},{ }^{*}}$ Emilie Courbon, ${ }^{\mathrm{c}}$ Anastasia Permyakova, ${ }^{\mathrm{b}}$ Farid Nouar, ${ }^{\mathrm{d}}$ Corine Simonnet-Jégat, ${ }^{\mathrm{b}}$ Flavien Bourdreux, ${ }^{b}$ Loïc Malet, ${ }^{a}$ Christian Serre, ${ }^{\mathrm{d}}$ Marc Frère, ${ }^{\mathrm{c}}$ and Nathalie Steunou ${ }^{\mathrm{b}}$

${ }^{*}$ Corresponding author, pdans@ulb.ac.be

${ }^{a}$ Université libre de Bruxelles (ULB), 4MAT Department, 50 Avenue F.D. Roosevelt, CP194/03, 1050 Brussels, Belgium (partly detached at UMONS, see below).

b Institut Lavoisier, UMR CNRS 8180, Université de Versailles St-Quentin en Yvelines, 45 Avenue des Etats-Unis, 78035 Versailles Cedex, Université Paris-Saclay, France

${ }^{\circ}$ UMONS, Institut de Recherche en Energie - Laboratoire de Thermodynamique, 31 Boulevard Dolez, 7000 Mons, Belgium.

${ }^{d}$ Institut des Matériaux Poreux de Paris, UMR 8004 CNRS, Ecole Normale Supérieure, Ecole supérieure de physique et de chimie Industrielles de la ville de Paris, PSL University, 75005 Paris, France.

\begin{abstract}
Seasonal heat storage technologies are the key for a widespread use of solar thermal energy in residential applications. This can be achieved using hygroscopic salts encapsulated in a porous matrix with a high pore volume. Using strontium bromide encapsulated in the mesoporous MIL-101(Cr) Metal-Organic Framework, a heat storage density of $233 \mathrm{kWh} / \mathrm{m}^{3}$ could be achieved, by using water vapor at a partial pressure as low as $1.25 \mathrm{kPa}$. This excellent result is partly due to the high salt content (63 wt. \%), but also to unexpected modifications of the water sorption isotherms of $\mathrm{SrBr}_{2}$ once it is encapsulated. At a temperature of $30^{\circ} \mathrm{C}$, ideal for space heating in low energy dwellings, it may be suggested that the salt is partially soluble upon water sorption.
\end{abstract}

\section{Keywords}

Composite material; thermochemical heat storage; strontium bromide; metal-organic framework (MOF); mesoporous material; sorption.

\section{Research highlights}

$\mathrm{SrBr}_{2}$ can be encapsulated until 63 wt. \% in MIL-101(Cr).

The composite stores $0.375 \mathrm{Wh} / \mathrm{g}$ or $233 \mathrm{kWh} / \mathrm{m}^{3}$ in residential heat storage conditions.

It requires water exchange between $30^{\circ} \mathrm{C}$ and $80^{\circ} \mathrm{C}$ at only $1.25 \mathrm{kPa}$ partial pressure.

Chemi- and physisorption are not sufficient to interpret this remarkable behaviour.

\section{Acronyms}

BET: Brunauer-Emmett-Teller

FTIR: Fourier transformed infrared spectrometry

ICP: Inductively coupled plasma

MIL-...: "Matériaux de 1'Institut Lavoisier" (class of MOFs developed at the University of Versailles SaintQuentin en Yvelines)

MOF: Metal-organic framework

P: $\quad$ Pressure

$\mathrm{P}^{\circ}$ : Atmospheric pressure

PXRD: Powder X-ray diffraction

SC: $\quad$ Salt content

SEM-EDX: Scanning electron microscope and energy-dispersive X-ray spectrometer 
T: $\quad$ Temperature

TEM: Transmission electron microscope

TG-DSC: Thermogravimetric analyzer coupled with differential scanning calorimetry

$\begin{array}{ll}\mathrm{V}: & \text { Volume } \\ \Delta \mathrm{H}_{\mathrm{r}}: & \text { Enthalpy of reaction } \\ \rho: & \text { Density }\end{array}$

\section{INTRODUCTION}

Solar thermal collectors are a cheap and efficient way to produce domestic heat. Combined with sensible heat storage at the scale of several hours, these are widespread for sanitary hot water production. In such a case, the heat is stored during several hours in water tanks, using the sensible heat of water. No compact and affordable technology is available yet when the heat demand is deferred by more than several days from the solar energy availability. Such a long term "thermal battery" would overcome the inherent seasonality of solar energy. This would make it possible to store energy from solar collectors for residential space heating during wintertime, for intermediate latitudes. In E.U., this application represents $25 \%$ of the final energy consumption [1].

For seasonal heating of low energy buildings, the ideal thermal battery material is charged using solar collectors at $80^{\circ} \mathrm{C}$ or higher in specific conditions, delivers heat with no loss at $30^{\circ} \mathrm{C}$, stores enough heat for the winter in $\sim 10 \mathrm{~m}^{3}$ and is stable after $>10$ discharging cycles. The storage in water tanks is not compact enough and suffers from thermal losses on the long term.

Regarding this seasonal heating application, several thermal energy storage systems have been proposed so far. They differ from each other by the type of reactor or by the storage medium.

Regarding the heat storage medium, a high heat storage density and a good multi-cycle stability at limited cost are key requirements. They are more likely to be met by systems using thermochemical phenomena and/or ab/adsorption phenomena involving the exchange of water molecules. An example of this is the exchange of water molecules by salt hydrates [2]. For these materials, the heat storage density is linked to the cycle loading lift, which is the mass of sorbent exchanged between the sorption and desorption step, defined by their respective temperature and water partial pressure [3]. Salts like $\mathrm{CaCl}_{2}$ [4], $\mathrm{MgCl}_{2}$ [5], $\mathrm{MgSO}_{4}[6]$ and $\mathrm{SrBr}_{2}$ [7-11] are proposed in the thermal engineering literature. Other temperature ranges (negative to $900^{\circ} \mathrm{C}$ ) are reviewed in [12]. In contrast, phase change materials are rather used for peak shaving applications, to increase the efficiency of other measures [13], with the exception of some systems based on transformations between organic isomers [14]. Sorbents and reactors are reviewed in [15, 16].

In an extensive screening on pure salts, N'Tsoukpoe et al. consider that only $\mathrm{SrBr}_{2}$ and $\mathrm{LaCl}_{3}$ are suitable for sanitary hot water and space heating [17]. Putting aside $\mathrm{LaCl}_{3}$ due to $\mathrm{La}$ scarcity, $\mathrm{SrBr}_{2}$ should be thus considered in priority since it is possible to produce it from widespread resources [18]. The exploited hydrates are the mono- and hexahydrate forms; the anhydrous form appears at high temperature only [17]. Its theoretical energy storage density is $628 \mathrm{kWh} / \mathrm{m}^{3}$. In case of excessive exposure to water vapor, $\mathrm{SrBr}_{2} \cdot 6 \mathrm{H}_{2} \mathrm{O}$ is dissolved into an aqueous solution of $\mathrm{Sr}^{2+}$ and $\mathrm{Br}^{-}$. It was previously reported that the encapsulation of the salt in a porous matrix is effective in preventing or limiting the leaching of the salt and improving its stability [19]. Strontium bromide being corrosive, this stability is essential for the surrounding equipment [20]. Nevertheless, $\mathrm{SrBr}_{2}$ is less prone to dissolve than other candidates like $\mathrm{CaCl}_{2}$. A review on its use in energy storage systems was published by Fopah-Lele and Tamba [19]. Recently, some of us reported a high energy storage density of $203 \mathrm{kWh} / \mathrm{m}^{3}$ for $\mathrm{SrBr}_{2}$ encapsulated in mesoporous silica gel with a rather limited pore volume [21]. It remains low compared to the pure salt energy density and further motivates to encapsulate the salt in a high pore volume matrix. Most of the time, the salts are encapsulated in an inert matrix like expanded graphite [7], zeolite [22, 23] or activated carbon [24] for reversibility reasons. Recently, ordered porous hybrid solids such as Metal-Organic Frameworks (MOFs) were proposed for this purpose.

Intrinsically, MOFs are a promising class of porous hybrid materials for water sorption systems due to their large structural and chemical diversity leading to ranges of micro or mesoporous solids with a tunable hydrophilic/hydrophobic balance. It has been demonstrated that MOFs could compete with benchmark inorganic porous solids for heat pumps [25], low temperature heating and cooling [26], heating [27] and refrigeration or air-conditioning applications $[28,29]$. In a recent review, Henninger et al. considered MIL- 
100(Al), aluminium fumarate, CAU-10-H and MIL-101(Cr) as possible candidates, for their high water uptakes, their hydrophilicity and the S-shape of their adsorption isotherms [30]. For residential heating applications, Permyakova et al. proposed hydrophilic MIL-160(Al) that adsorbs $0.36 \mathrm{~g} / \mathrm{g}$ at $30^{\circ} \mathrm{C}$ for $\mathrm{p}_{\text {water }}$ as low as $1.25 \mathrm{kPa}$. This allows using a cheap heat source at $10^{\circ} \mathrm{C}$ to evaporate water, to produce as much as $314 \mathrm{Wh} / \mathrm{kg}$ during the winter, close to salt hydrates. Similar results have been obtained using MIL-100(Fe), UiO-66(Zr)- $\mathrm{NH}_{2}$ and MIL-125(Ti)- $\mathrm{NH}_{2}$ [31]. In contrast, chromium terephtalate or MIL-101(Cr) is able to adsorb more than its own weight of water. This was observed in studies on dehumidication $\left(1.6 \mathrm{~g} / \mathrm{g}\right.$ at $30^{\circ} \mathrm{C}$ and $60 \%$ humidity [32]) and thermal applications $\left(1 \mathrm{~g} / \mathrm{g}\right.$ at $25^{\circ} \mathrm{C}[33] ; 900 \mathrm{~kg} / \mathrm{m}^{3}$ at $23^{\circ} \mathrm{C}[34] ; 1.1 \mathrm{~g} / \mathrm{g}$ at $20^{\circ} \mathrm{C}$ [35]; $\sim 1.25 \mathrm{~g} / \mathrm{g}$ at $25^{\circ} \mathrm{C}[36]$ and generally lower for the functionalised forms [37]). However, the sorption remains low at low water partial pressure. Due to its poorly hydrophilic character, the adsorption step of MIL 101(Cr) occurs at a converging range of $\mathrm{p} / \mathrm{p}^{\circ}=0.4-0.5$ in these studies.

This paper deals with the synthesis of a novel composite sorbent for energy storage applications, through the encapsulation of $\mathrm{SrBr}_{2}$ in a MOF host matrix. A few MOFs based composites were recently reported for heat storage applications. Luan et al. used MIL-101- $\mathrm{NH}_{2}$ as frameworks to support fatty acid for thermal applications [38]. The loading of $\mathrm{CaCl}_{2}$ into UIO-66( $\mathrm{Zr}$ ) (or its $\mathrm{NH}_{2}$ functionalized analog, UIO-66( $\mathrm{Zr}$ )- $\mathrm{NH}_{2}$ ) was considered for the preparation of composites for adsorption thermal batteries or chillers applications with interesting heat storage capacity, good specific cooling power and cycling stability [39].

Recently, some of us have reported a series of MOFs- $\mathrm{CaCl}_{2}$ composites based on MOFs differing by their hydrophilic/hydrophobic balance, pore size/shape and pore volumes. We have shown that two mesoporous MOFs- $\mathrm{CaCl}_{2}$ composites (i.e., MIL- $100(\mathrm{Fe}) / \mathrm{CaCl}_{2}$ and $\mathrm{MLL}-101(\mathrm{Cr}) / \mathrm{CaCl}_{2}$ ) with the highest salt content (46 and 62 wt. \% respectively), presented very high energy storage capacities (up to $310 \mathrm{kWh} \cdot \mathrm{m}^{-3}$ (485 Wh. $\left.\mathrm{kg}^{-1}\right)$ ) outperforming the best sorbents reported so far together with a very good adsorption-desorption multi-cycles stability [3].

Such interesting results motivated us to use the mesoporous and amphiphilic MIL-101(Cr) MOF as a host matrix of $\mathrm{SrBr}_{2}$. MIL-101(Cr) is composed of two mesoporous cages of different sizes (about $29 \AA$ and 34 $\AA$ ) separated by pentagonal and hexagonal windows of at least 12 and $16 \AA$ diameter, respectively (fig. 1) [40].

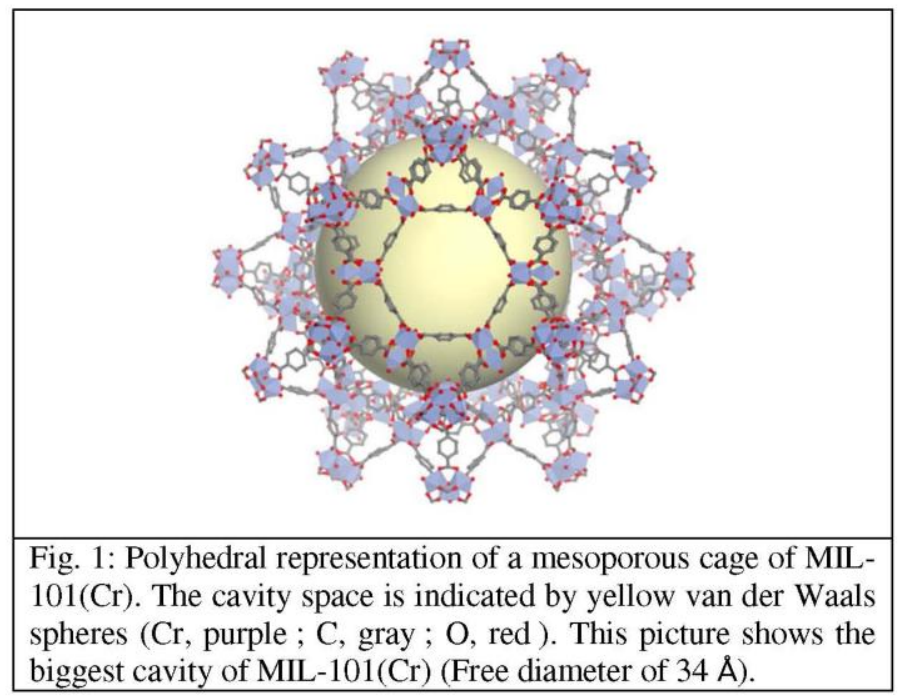

This paper aims to evaluate the performance of the $\mathrm{SrBr}_{2}-\mathrm{MIL}-101(\mathrm{Cr})$ material for seasonal heat storage application and potentially explain how the structural and physico-chemical properties of this composite may impact its water sorption properties.

\section{EXPERIMENTAL SECTION}

\subsection{Synthesis of $\mathrm{MIL}-101(\mathrm{Cr}) / \mathrm{SrBr}_{2}$ composite}

The wet impregnation method previously reported for the synthesis of MOF-composites [41] was used to synthesize MIL-101(Cr)/ $\mathrm{SrBr}_{2}$ composites. An amount of MIL-101(Cr) particles was dispersed in aqueous solutions of $\mathrm{SrBr}_{2}$ with concentrations ranging between 20 and $40 \mathrm{wt} \%$. Our objective was to optimize the salt content in the MIL-101(Cr)/ $\mathrm{SrBr}_{2}$ composites. Among different composites, two of them were selected 
and then characterized. $800 \mu \mathrm{L}$ of 30 wt. $\% \mathrm{SrBr}_{2}$ solution were mixed with $150 \mathrm{mg} \mathrm{MLL}-101(\mathrm{Cr})$ in an Eppendorf flask. The sample was stirred for 2 hours at room temperature. Then the solution was separated twice by centrifugation $(14000 \mathrm{rpm}, 2 \mathrm{~min})$ and by removing the supernatant. The sample was finally dried at $100^{\circ} \mathrm{C}$ for 4 hours. In an attempt to further increase the salt content in the porosity of $\mathrm{MIL}-101(\mathrm{Cr})$, the synthesis was also performed by using a $40 \mathrm{wt}$ \% $\mathrm{SrBr}_{2}$ solution.

\subsection{Chemical and structural characterization}

Powder X-ray diffraction (PXRD) patterns were obtained on a Bruker D8 Advance vario1 diffractometer using pure $\mathrm{CuK} \alpha 1$ radiation $(\lambda=1.540598 \AA)$ and equipped with an Anton Paar HTK1200N high temperature chamber. The PXRD diagrams were collected at $30^{\circ} \mathrm{C}$ and $150^{\circ} \mathrm{C}$ between 3 and $60^{\circ}(2 \theta)$ with a step of $\sim 0.02^{\circ}(2 \theta)$. Nitrogen adsorption was performed at $77 \mathrm{~K}$ on a Belsorp max equipment. Prior to the analysis, samples were dried for $7 \mathrm{~h}$ at $180^{\circ} \mathrm{C}$. BET surface and micropore volume were estimated at a relative pressure below 0.25 .

SEM-EDX analysis was performed on a JEOL JSM-7001F microscope using gold-coated samples equipped with an energy-dispersive X-ray (EDX) spectrometer and a X-Max SDD (Silicon Drift Detector) by Oxford. Transmission electron microscopy (TEM) was performed on a CM20 (Philips) equipment. Samples were prepared by deposition of one droplet of colloidal suspensions onto a carbon-coated copper grid and left to dry in air. In order to determine the composition of the composite, $4 \mathrm{mg}$ of composite were dissociated in 1 $\mathrm{mL}$ sulfuric acid at $100^{\circ} \mathrm{C}$ overnight in closed Eppendorf flasks. They were diluted in milliQ in water until $50 \mathrm{~mL}$ just. The $\mathrm{Sr}$ and $\mathrm{Cr}$ contents in the composite were determined by Inductively Coupled Plasma (ICP). FTIR spectra (absorption mode) were acquired on a Thermo Scientific Nicolet iS10 spectrometer from room temperature to $150^{\circ} \mathrm{C}$, with a Praying Mantis ${ }^{\mathrm{TM}}$ module equipped with a high temperature reaction chamber (Harrick scientific products). The temperature increasing rate is $2^{\circ} \mathrm{C} / \mathrm{min}$. A plateau of $20 \mathrm{~min}$ at $150^{\circ} \mathrm{C}$ is then applied.

\subsection{Water sorption and calorimetric measurements}

The cycle loading lift and the heat storage capacity measurements were performed using a thermogravimetric analyzer coupled with differential scanning calorimetry (TG-DSC111 from Setaram) and a humidity generator (Wetsys from Setaram). Prior to experiments, the sample was dried at $200^{\circ} \mathrm{C}$ for $10 \mathrm{~h}$ (heating rate: $1^{\circ} \mathrm{C} / \mathrm{min}, 50 \mathrm{~mL} / \mathrm{min}$ dry nitrogen $)$. The dry sample $(17.49 \mathrm{mg}$ ) was then exposed to an adsorption/desorption cycle under humid nitrogen $(1.25 \mathrm{kPa}$ water partial pressure, $50 \mathrm{~mL} / \mathrm{min})$ at $30-80^{\circ} \mathrm{C}$, representative of space heating conditions. The sample was exposed at $30^{\circ} \mathrm{C}$ until the equilibrium, after which it was heated at a rate of $1^{\circ} \mathrm{C} / \mathrm{min}$ until $80^{\circ} \mathrm{C}$, then cooled at the same rate until $30^{\circ} \mathrm{C}$. During all the cycle, the mass and the heat flow were recorded. The heat storage capacity was obtained by integrating the heat flow signal. The same test was performed using an empty crucible, so as to remove its sensible heat from the heat flow signal. A correction was also applied, in order to account for the heat capacity of the composite. The cycle loading lift was obtained by mass difference between the lower and upper temperature of the cycle.

In order to study the influence of the sorption temperature, the water mass adsorbed at equilibrium was measured at other temperatures $\left(40^{\circ} \mathrm{C}, 50^{\circ} \mathrm{C}\right.$ and $\left.120^{\circ} \mathrm{C}\right)$, while keeping the same water pressure of $1.25 \mathrm{kPa}$. The results are presented as a sorption isobar.

The $30-80^{\circ} \mathrm{C}$ cycle experiment was repeated, in order to obtain the cycle loading lift after 10 cycles. For this multi-cycle stability test, a sample of MIL- $101(\mathrm{Cr})-\mathrm{SrBr}_{2}$ was dried at $200^{\circ} \mathrm{C}$ for 10 hours under dry nitrogen prior to the measurements (anhydrous mass $=21.36 \mathrm{mg}$ ).

A water sorption isotherm was collected using an IGASorp instrument (Hiden Isochema). $23 \mathrm{mg}$ of sample were first dried at $200^{\circ} \mathrm{C}$ for 10 hours under dry nitrogen $(250 \mathrm{~mL} / \mathrm{min})$. The isotherm was performed at $30^{\circ} \mathrm{C}$, with a gas flow of $250 \mathrm{~mL} / \mathrm{min}$. Both sorption and desorption were studied.

\section{RESUlTS AND DISCUSSION}

\subsection{Synthesis and characterization of $\mathrm{MIL}-101(\mathrm{Cr}) / \mathrm{SrBr} r_{2}$ composite}

Composites combining $\mathrm{SrBr}_{2}$ and $\mathrm{MIL}-101(\mathrm{Cr})$ as a host matrix were prepared through the impregnation of MOF powder with aqueous solutions of different $\mathrm{SrBr}_{2}$ concentrations ranging between 20 and 40 wt. $\%$, Our objective was to synthesize MIL-101(Cr)/ $\mathrm{SrBr}_{2}$ composites with an optimal content of $\mathrm{SrBr}_{2}$ in the MOF 
pores but without any recrystallization of the salt at the surface of MOF particles. These materials were characterized by PXRD at $150^{\circ} \mathrm{C}$ and $30^{\circ} \mathrm{C}$ (see fig. 2). Figure 2 show the X-ray diffraction patterns of MIL$101(\mathrm{Cr}) / \mathrm{SrBr}_{2}$ composites with a $\mathrm{SrBr}_{2}$ content of 30 and $40 \mathrm{wt} \%$. They are fully consistent with that of pure $\mathrm{ML}-101(\mathrm{Cr})$ indicating, that the structure of $\mathrm{ML}-101(\mathrm{Cr})$ is fully preserved in composites. It is worth noting a significant decrease of relative intensity of diffraction Bragg peaks at $30^{\circ}$, especially at low angle, as a result of a modification of the electronic density (and thus a strong absorbance of the X-ray by the materials) as well as a strong disorder of the hydrated salt in the mesoporous cages. Such phenomenon was previously observed for composites combining $\mathrm{CaCl}_{2}$ and large pore MOFs (i.e., $\mathrm{ML}-100(\mathrm{Fe})$ and $\mathrm{MIL}$ 101(Cr) ) [3]. Therefore PXRD patterns were also recorded on dehydrated samples at $150^{\circ} \mathrm{C}$. For the composite with the highest salt content (i.e., prepared with a $40 \mathrm{wt}$ \% $\mathrm{SrBr}_{2}$ solution), the PXRD pattern of $\mathrm{MIL}-101(\mathrm{Cr})$ is superimposed with that of $\mathrm{SrBr}_{2} \cdot 6 \mathrm{H}_{2} \mathrm{O}$ and $\mathrm{SrBr}_{2} \cdot \mathrm{H}_{2} \mathrm{O}$ at $30{ }^{\circ} \mathrm{C}$ and $150^{\circ} \mathrm{C}$ respectively, confirming that the structural integrity of the MOF is kept upon loading with $\mathrm{SrBr}_{2}$. At $150^{\circ} \mathrm{C}$, the salt is partially dehydrated which is typical of the behaviour of the bulk salt. The presence of $\mathrm{SrBr}_{2}$ hydrates is likely to be due to a recrystallization of a small amount of salt at the outer surface of MIL-101(Cr) particles. For the composite with the lowest salt content (i.e., prepared with a $30 \mathrm{wt}$. \% $\mathrm{SrBr}_{2}$ solution), the PXRD pattern recorded at both temperatures do not display any peak that can be attributed to any form of strontium bromide, suggesting that the salt is totally encapsulated inside the porosity of the MOF matrix. The recrystallization of the salt in the inter-particle space of MOF particles is detrimental for the stability of composites upon adsorption/desorption cycles and thus for their performance. Therefore, the composite with the lowest salt content (i.e., prepared with a $30 \mathrm{wt}$. \% $\mathrm{SrBr}_{2}$ solution) was considered for the following studies of microstructural characterization and water sorption.

In order to determine the salt content of the composite, three methods were combined. First, the elemental mapping was performed by EDX analysis on three representative rectangular surfaces of the sample (see SI). The salt content lies in the range 61-65 wt. \% and is on the whole similar for 3 areas of the composite, confirming the homogeneous distribution of salt among the different MOF particles. Secondly, the salt content could be evaluated by considering the pore volumes of the MIL-101(Cr) matrix $\mathrm{V}_{\mathrm{p}, \mathrm{ML}-101}$ and composite $\mathrm{V}_{\mathrm{p}, \mathrm{composite}}$ extracted from BET measurements (fig. 3) and assuming that the salt occupies solely the pore volume of $\mathrm{MIL}-101(\mathrm{Cr})$ and thus the difference of volume between MIL-101(Cr) and composite. It could be calculated according to the equation:

$$
\mathrm{SC}_{\mathrm{BET}}=\frac{\mathrm{V}_{\mathrm{p}, \mathrm{ML} \text { 101 }}-\mathrm{V}_{\mathrm{p}, \text { composite }}}{\mathrm{V}_{\mathrm{p}, \mathrm{MLL} 101}+\frac{1}{\rho_{\text {salt }}}}
$$

where $\rho_{\text {salt }}$ is the salt density of the anhydrous $\operatorname{SrBr}_{2}\left(\rho_{\text {salt }}=4.21 \mathrm{~g} \cdot \mathrm{cm}^{-3}\right)$. Such an approach was previously used to evaluate the $\mathrm{CaCl}_{2}$ content of silica based sorbent [42]. A salt content close to 61 wt. \% was thus calculated, in very good agreement with EDX analysis. Finally, a salt content of 67 wt. \% was determined by ICP analysis and is slightly higher than the values given by EDX or BET measurements. It is noteworthy that the salt content evaluated by ICP is based on the $\mathrm{Cr} / \mathrm{Sr}$ ratio, assuming that the $\mathrm{Br} / \mathrm{Sr}$ molar ratio is equal to 2 . However, according to EDX analysis (see SI), the $\mathrm{Br} / \mathrm{Sr}$ is presumably lower than 2 . This slight lack of anion content in the composite may be explained by the high size of the $\mathrm{Br}^{-}$anion that may impact its accommodation in the mesoporous cages of the MOF and the charge matching between the salt and the MOF framework, as previously reported for $\mathrm{CaCl}_{2}-\mathrm{MOF}$ composites [3]. Nevertheless, these three methods provide consistent results and one can estimate that the $\mathrm{MIL}-101(\mathrm{Cr}) / \mathrm{SrBr}_{2}$ composite contains $63 \pm 4$ wt. \% of $\mathrm{SrBr}_{2}$. In the following, this composite was labelled as $\mathrm{MIL}-101(\mathrm{Cr}) / \mathrm{SrBr}_{2}(63 \%)$.

Nitrogen adsorption measurements were performed in order to gain information on the residual porosity of composites (fig. 3). The pore volume and BET surface area of $\mathrm{ML}-101(\mathrm{Cr}) / \mathrm{SrBr}_{2}(63 \%)$ are as expected considerably reduced in comparison to pure $\mathrm{MIL}-101(\mathrm{Cr})\left(0.44 \mathrm{~cm}^{3} \cdot \mathrm{g}^{-1}\right.$ versus $1.51 \mathrm{~cm}^{3} \cdot \mathrm{g}^{-1}$ and $603 \mathrm{~m}^{2} \cdot \mathrm{g}^{-1}$ versus $3700 \mathrm{~m}^{2} \cdot \mathrm{g}^{-1}$ ), confirming that the salt is encapsulated in the mesoporous cages of the MOF. However, the composite still exhibits a residual porosity that may be of interest in water adsorption of these materials. SEM images show that both composites consist of aggregates of MOF particles (supplementary information) with no micrometer-sized $\mathrm{SrBr}_{2}$ crystals. Additional TEM images (fig. 4 a-c) were recorded, showing the characteristic octahedral morphology of $\mathrm{MIL}-101(\mathrm{Cr})$ particles, thereby confirming the stability of the MOF upon the salt encapsulation. An EDX spectrum acquired on a single particle (fig. $4 \mathrm{~d}$ ) confirms the encapsulation of $\mathrm{SrBr}_{2}$ in the porosity of $\mathrm{ML}-101(\mathrm{Cr})$. The $\mathrm{MLL}-101(\mathrm{Cr}) / \mathrm{SrBr}_{2}(63 \%)$ was finally characterized by FTIR spectroscopy. Figures S5-S8 display the FTIR spectra of the composite, MIL-101(Cr) 
and salt at various temperatures. Figure S5 gives specifically the data recorded at $30^{\circ} \mathrm{C}$ and $150^{\circ} \mathrm{C}$ in comparison to the parental MOF at $30^{\circ} \mathrm{C}$. The characteristic vibration bands of the MOF are clearly identified in the FTIR spectra of the composite. In particular, the bands at 1630 and $1380 \mathrm{~cm}^{-1}$ correspond to the stretching vibration bands of the carboxylate linked to the $\mathrm{Cr}$ atom of the MOF. This FTIR analysis confirms the stability of the ML-101(Cr) structure upon the salt encapsulation. 

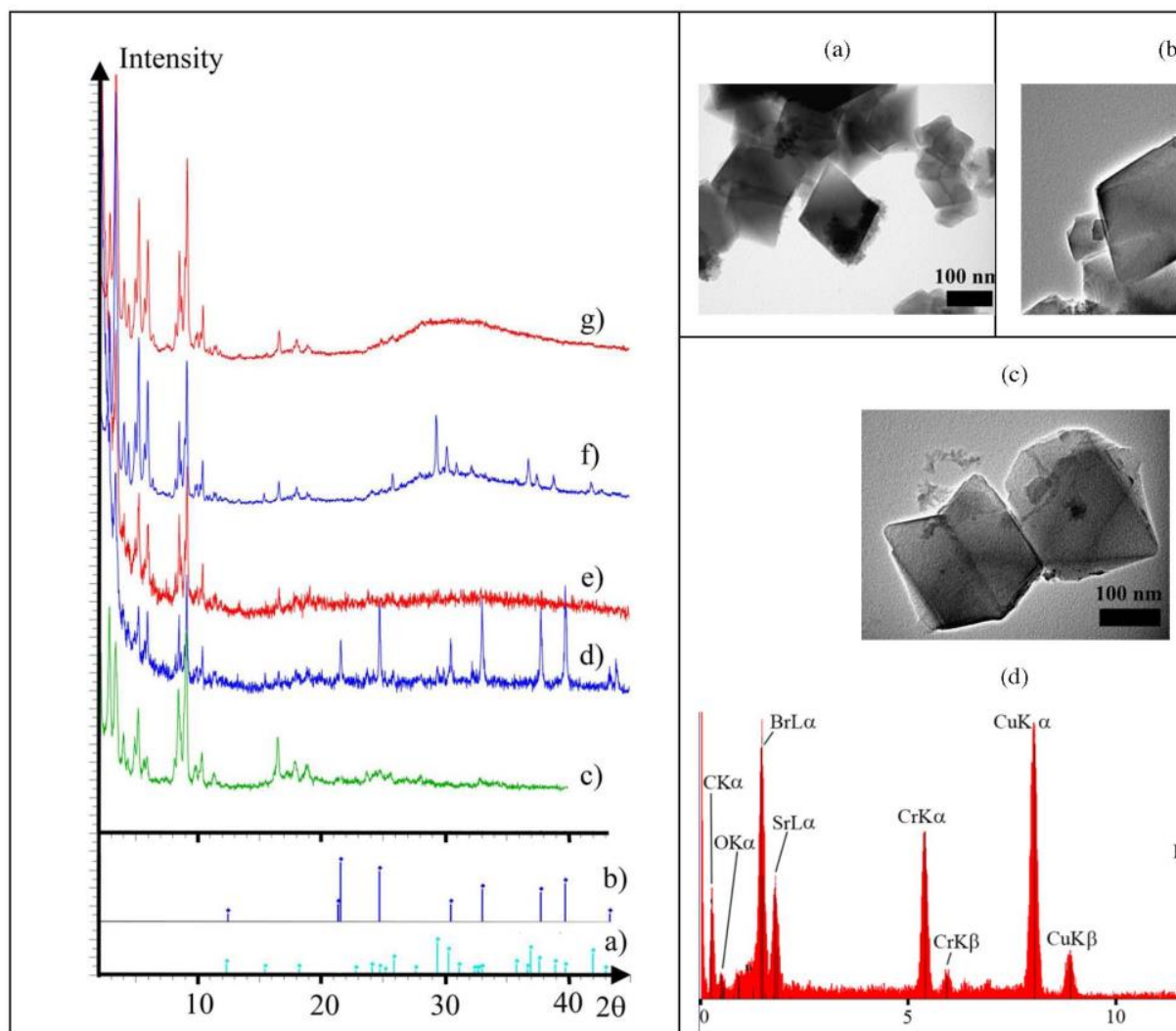

(b)

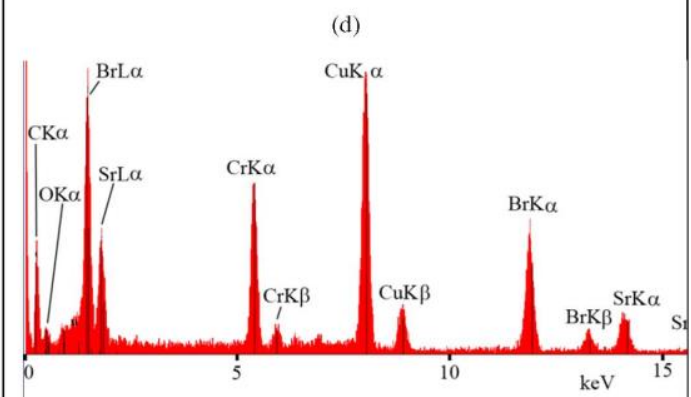

Fig. 4: (a-c) TEM images of MIL-101(Cr)-SrBr2

Fig. 2: PXRD patterns of the materials under study, using the $\mathrm{K} \alpha$ ray of $\mathrm{Cu}(1.54056 \AA)$ :

(63\%); (d) EDX measurement. Note that $\mathrm{Cu}$ peaks are due to the $\mathrm{Cu}$ grid.

of $\mathrm{SrBr}_{2} \mathrm{H}_{2} \mathrm{O}$;

b) theoretical pattern of $\mathrm{SrBr}_{2} \cdot 6 \mathrm{H}_{2} \mathrm{O}$;

c) MIL-101(Cr);

d) $\mathrm{MIL}-101(\mathrm{Cr})-\mathrm{SrBr}_{2}$ from a $40 \%$ solution, measured at $30^{\circ} \mathrm{C}$;

e) id. from a $30 \%$ solution, at $30^{\circ} \mathrm{C}$;

f) id. from a $40 \%$ solution, at $150^{\circ} \mathrm{C}$;

g) id. from a $30 \%$ solution, at $150^{\circ} \mathrm{C}$.

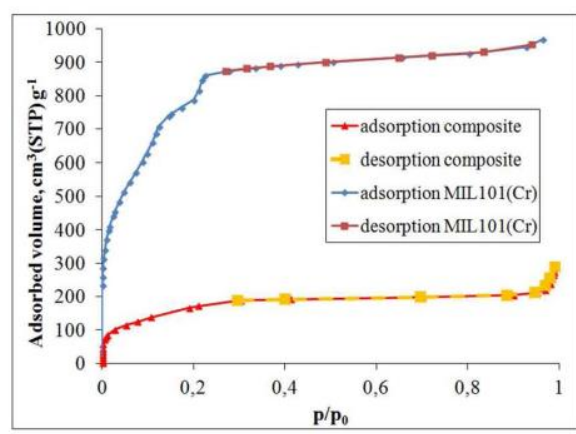

Fig. 3: Nitrogen sorption isotherm (77 K, $\left.\mathrm{P}_{0}=1 \mathrm{~atm}\right)$ of $\mathrm{MIL}-101(\mathrm{Cr})$ [3] and composite $\mathrm{MIL}-101(\mathrm{Cr}) / \mathrm{SrBr}_{2}$ $(63 \%)$. Estimations for the composite: specific surface: $603 \mathrm{~m}^{2} / \mathrm{g}$; pore volume: $0.44 \mathrm{~cm}^{3} / \mathrm{g}$. 


\subsection{Water sorption properties and heat storage performance of $\mathrm{MLL}-101(\mathrm{Cr}) / \mathrm{SrBr}_{2}(63 \%)$}

The water sorption behaviour of $\mathrm{ML}-101(\mathrm{Cr}) / \mathrm{SrBr}_{2}(63 \%)$ was studied using conditions of a seasonal energy storage system. In case of this application, the difference of mass between adsorption conditions (representative of the winter heat release mode) and desorption conditions (representative of the summer heat storage mode) defined as the cycle loading lift is a relevant parameter to characterize the performance of a thermochemical storage material. Cycle loading lifts were thus measured in the following operating conditions: $\mathrm{T}_{d}=80^{\circ} \mathrm{C}$ (desorption temperature typical of a solar collector), $\mathrm{T}_{\mathrm{a}}=30^{\circ} \mathrm{C}$ (minimum adsorption temperature for space heating at winter period) while the evaporating and condensing temperatures of $10^{\circ} \mathrm{C}$ $\left(\mathrm{T}_{\mathrm{e}}, \mathrm{T}_{\mathrm{c}}\right.$ ) corresponding to a pressure of $1.25 \mathrm{kPa}$ for a closed system were chosen. The mass change was considered in gram of water per gram of anhydrous composite measured between $30^{\circ} \mathrm{C}$ and $80^{\circ} \mathrm{C}$ at 1.25 $\mathrm{kPa}$. The cycle loading lift of the composite is compared to that of the pure MOF (mass of water/mass of dry $\mathrm{MOF}$ ) and that of the pure salt (mass of water/mass of dry salt) (table 1).

Table 1: Sorption properties of $\mathrm{ML}-101(\mathrm{Cr}) / \mathrm{SrBr}_{2}(63 \%)$ and $\mathrm{MIL}-101(\mathrm{Cr})$, for a constant water vapor pressure of $1.25 \mathrm{kPa}$, and for cycles of $30-80^{\circ} \mathrm{C}$. For $\mathrm{SrBr}_{2}$, the values are theoretical and correspond to the cycling between $\mathrm{SrBr}_{2} \cdot \mathrm{H}_{2} \mathrm{O}$ and $\mathrm{SrBr}_{2} \cdot 6 \mathrm{H}_{2} \mathrm{O}$. The two last lines correspond to scenarios proposed in the text.

\begin{tabular}{|l|l|l|}
\hline Material & $\begin{array}{l}\text { Cycle loading lift } \\
\text { g water /g dry material }\end{array}$ & $\begin{array}{l}\text { Energy storage capacity } \\
\text { Wh /g dry material }\end{array}$ \\
\hline MIL-101(Cr)/SrBr $2(63 \%)$, exp. & 0.303 & 0.375 \\
\hline MIL-101(Cr), exp. [31] & 0.121 & 0.087 \\
\hline $\mathrm{SrBr}_{2}$, theor. $[9,43]$ & 0.362 & 0.379 \\
\hline MIL-101(Cr)/SrBr 2, scenario 1 & $\begin{array}{l}0.303 \text { of which 0.073 } \\
\text { physisorption }\end{array}$ & 0.291 \\
\hline MIL-101(Cr)/SrBr 2, scenario 2 & 0.303 , only absorption & 0.309 \\
\hline
\end{tabular}

The energy storage capacity of $\mathrm{MIL}-101(\mathrm{Cr}) / \mathrm{SrBr}_{2} \quad(63 \%)$ measured experimentally through microcalorimetric measurements is $0.375 \mathrm{Wh} \cdot \mathrm{g}^{-1}$. It corresponds to an experimental energy storage density of $233 \mathrm{kWh} . \mathrm{m}^{-3}$ by taking into account the packing density of the composite in its powdered form (i.e., 622 $\left.\mathrm{kg} / \mathrm{m}^{3}\right)$. Although the shaping of the MIL- $101(\mathrm{Cr}) / \mathrm{SrBr}_{2}(63 \%)$ was not performed yet, its performance is superior or comparable to that of the most promising MOFs and silica based composites previously reported and studied under identical operating conditions (see table 2). It is worth noting that the water sorption properties of materials are strongly dependent on the cycle boundary conditions and the energy storage density values between materials should be compared under the same operating conditions.

On Table 1, it can be seen that the composite materials performs better than MIL-101(Cr) alone. It performs nearly as well as the theoretical performances of the salt, but with no more than $63 \mathrm{wt}$. \% of salt in its porosity.

A scenario ("scenario 1" in Table 1) is proposed to interpret these values. It is assumed that:

(i) Chemisorption occurs for the salt fraction, i.e., the exchange of 5 molecules $\mathrm{H}_{2} \mathrm{O}$ between $\mathrm{SrBr}_{2} . \mathrm{H}_{2} \mathrm{O}$ and $\mathrm{SrBr}_{2} \cdot 6 \mathrm{H}_{2} \mathrm{O}$.

(ii) All the remaining sorption is assumed to be physisorption in MOF.

The same interpretative scenario was already proposed for a $\mathrm{MIL}-101(\mathrm{Cr})-\mathrm{CaCl} 2$ composite in [3]. The results are given in table 1 and the details, in SI, section 3. An energy storage capacity of only $0.291 \mathrm{Wh} / \mathrm{g}$ of dry composite is predicted, far below the experimental value. This indicates that the energy stored per sorbed water molecule is considerably higher than in pure physisorption, which is encouraging.

In order to clarify this apparent contradiction, a water sorption isotherm was recorded in order to shed light on the sorption mechanism of water on $\mathrm{MIL}-101(\mathrm{Cr}) / \mathrm{SrBr}_{2}(63 \%)$. 
Table 2: Comparison of composites (literature) with MIL-101(Cr)/ $\mathrm{SrBr}_{2}(63 \%)$ (this work) for space heating application

\begin{tabular}{|c|c|c|c|c|c|c|c|c|}
\hline Matrix & salt & $\begin{array}{c}\text { salt } \\
\text { content } \\
(\%, w t)\end{array}$ & $\begin{array}{l}\text { Energy storage } \\
\text { capacity (exp.) } \\
\text { (Wh/kg) }\end{array}$ & $\begin{array}{c}\text { Energy } \\
\text { storage } \\
\text { density (exp.) } \\
\left(\mathrm{kWh} / \mathrm{m}^{3}\right)\end{array}$ & $\begin{array}{l}\text { Adsorption } \\
\text { temperature } \\
\left({ }^{\circ} \mathrm{C}\right)\end{array}$ & $\begin{array}{l}\text { Adsorption } \\
\text { pressure, } \\
(\mathrm{kPa})\end{array}$ & $\begin{array}{c}\text { Desorption } \\
\text { temperature } \\
\left.{ }^{\circ} \mathrm{C}\right)\end{array}$ & Ref. \\
\hline MIL-101(Cr) & $\mathrm{SrBr}_{2}$ & 63 & 375 & 233 & 30 & 1.25 & 80 & This work \\
\hline MIL-100(Fe) & $\mathrm{CaCl}_{2}$ & 46 & $335^{\mathrm{a}} / 298^{\mathrm{b}}$ & $208^{a} / 185^{b}$ & 30 & 1.25 & 80 & {$[3]$} \\
\hline MIL-101(Cr) & $\mathrm{CaCl}_{2}$ & 62 & $485^{a} / 446^{D}$ & $310^{a} / 285^{b}$ & 30 & 1.25 & 80 & {$[3]$} \\
\hline $\begin{array}{l}\text { graphite treated with } \\
\text { sulfuric acid }\end{array}$ & $\mathrm{SrBr}_{2}$ & - & 140 & 113 & 35 & 1.71 & 80 & {$[11]$} \\
\hline Silica gel & $\mathrm{CaCl}_{2}$ & 43 & 300 & 211 & 30 & 1.25 & 80 & {$[42]$} \\
\hline Silica gel & $\mathrm{SrBr}_{2}$ & 58 & 230 & 203 & 30 & 1.25 & 80 & I2II \\
\hline Silica gel & $\mathrm{LiCl}$ & 35 & 254 & 163 & 40 & 1.70 & 90 & {$[41]$} \\
\hline Silica gel & $\mathrm{CaCl}_{2}$ & - & 283 & - & 30 & 3.39 & 90 & {$[41]$} \\
\hline Vermiculite & $\mathrm{LiCl}$ & 59 & 722 & 253 & 35 & 1.23 & 85 & i45] \\
\hline \multirow{2}{*}{$\begin{array}{c}\text { Carbon } \\
\text { Nano-tubes }\end{array}$} & $\mathrm{LiCl}$ & 44 & 470 & - & 35 & 0.87 & 75 & {$[46]$} \\
\hline & $\mathrm{CaCl}_{2}$ & 53 & 147 & - & 35 & 0.87 & 75 & {$[16]$} \\
\hline
\end{tabular}

\subsection{Water sorption isotherm of $\mathrm{MIL}-101(\mathrm{Cr}) / \mathrm{SrBr}_{2}(63 \%)$}

For the pure salt, water sorption isotherms should give two distinct horizontal segments, corresponding to the mono- and hexahydrate forms of $\mathrm{SrBr}_{2}$. On fig. 5, at $30^{\circ} \mathrm{C}$, no individual chemical reaction can be identified.

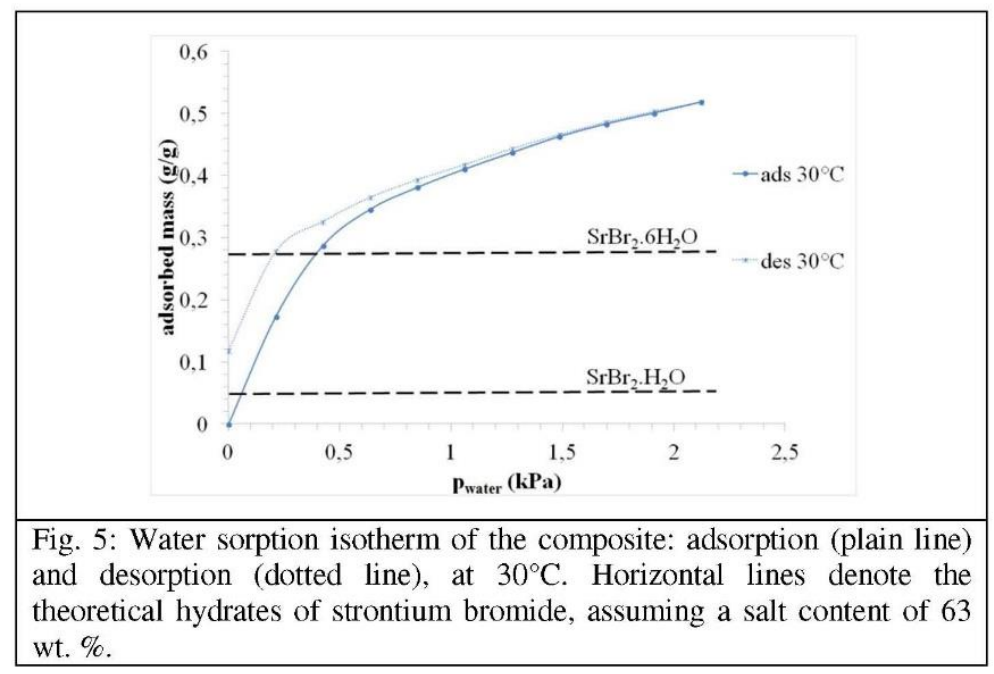

From this isotherm, a better understanding of the sorption mechanism in the composite can be gained. The absence of plateau for the hexahydrate indicates that the salt is not in the bulk solid state in the upper part of fig. 5. The shape of the isotherm suggests the presence of a salt solution in the pores rather than a hexahydrate, which is the basis for scenario $n^{\circ} 2$.

At $1.25 \mathrm{kPa}$, and $30^{\circ} \mathrm{C}$, strontium bromide is dissolved in about 10 molecules of water per $\mathrm{SrBr}_{2}$. This contrasts with the expected behaviour of the hexahydrate form of the salt as previously reported for $\mathrm{SrBr}_{2}$ silica gel based composite [21]. The absence of sorption plateau can be an asset since it leads to a 
progressive evolution of the performance and to more flexibility in case of variable working conditions. The enthalpy of the following reaction was thus considered in the second scenario:

$$
\begin{gathered}
\mathrm{SrBr}_{2} \cdot \mathrm{H}_{2} \mathrm{O}(\mathrm{s})+9 \mathrm{H}_{2} \mathrm{O}(\mathrm{g}) \rightarrow 10 \mathrm{H}_{2} \mathrm{O}(\mathrm{l})+\mathrm{Sr}^{2+}(\mathrm{aq})+2 \mathrm{Br}^{-}(\mathrm{aq}) \text { in } 10 \mathrm{H}_{2} \mathrm{O} \\
\Delta \mathrm{H}_{\mathrm{r}}=491 \mathrm{Wh} / \mathrm{kg} \text { dry composite }
\end{gathered}
$$

This value is based on data from [43]. The detailed calculations are given in SI, section 3 and the results are given in table 1 at the last line. A higher energy density of $192 \mathrm{kWh} / \mathrm{m}^{3}$ is thus calculated but it is still lower than the experimental value. Such discrepancy may be explained by different facts:

(i) Internal surfaces of MIL-101(Cr) framework in the composite material have a modified hydrophilic character compared to pure MIL-101(Cr). This is important, especially to explain the discrepancy of scenario 1.

(ii) We assumed in both scenarios that the driest form of the salt is the monohydrate and its enthalpy of formation is used in the calculations. In fig. 5, there is no evidence that the monohydrate form of $\mathrm{SrBr}_{2}$ exists inside the MOF. The salt lies in a disordered state inside the MOF porosity, which leads to different properties compared to the pure salt.

(iii) Furthermore, the above mentioned EDX analyses indicate a $\mathrm{Br}$ deficit in the composite. This further supports the idea of a disordered state of the salt and might explain the discrepancy in scenario 2 .

In conclusion, for both suggested scenarios, the already published sorption properties of the salt and the MOF are clearly enhanced.

\subsection{Stability upon adsorption-desorption cycle of $\mathrm{MIL}-101(\mathrm{Cr}) / \mathrm{SrBr}_{2}(63 \%)$}

Finally, in order to evaluate the multi-cycles stability of MIL-101(Cr)/ $\mathrm{SrBr}_{2}(63 \%)$ composite, this material was exposed to continuous water adsorption and desorption cycles in representative conditions of seasonal energy storage devices $\left(1.25 \mathrm{kPa}, 30-80^{\circ} \mathrm{C}\right)$. The cycle loading lift decreases of $14.1 \%$ after 10 cycles, of which $9.5 \%$ during the first 5 cycles. Thus, the decrease rate slows down from cycle to cycle. It results in a decrease of energy storage capacity of about the same order of magnitude (fig. 6). A similar behaviour was observed for $\mathrm{CaCl}_{2}-\mathrm{MIL}-101(\mathrm{Cr})$ composite [3] and may be explained by a possible leaching of the salt from the MOF host matrix. The water mass gain and loss were recorded during the cycles (supplementary information). This was done using the same device as for fig. 5. During the two first cycles, the initial slope of ad- and desorption kinetic curves given in S12-13 is smaller. The sample needs more time to take or release the water. The kinetics is thus slower and goes faster from the third cycle, suggesting again a change in the distribution or form of the salt within the MOF (see S12-13).

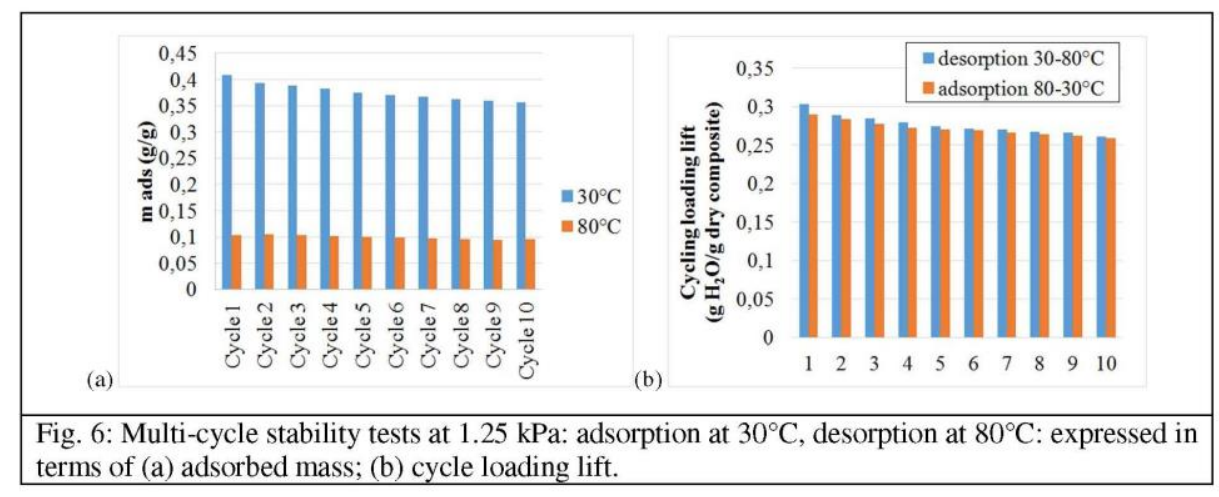

\subsection{Influence of the sorption temperature}

The water sorption performances are expected to depend on the conditions of sorption. In order to evaluate the influence of temperature on the water sorption performance of MIL-101(Cr)/ $\mathrm{SrBr}_{2}$ composite, an isobar at $1.25 \mathrm{kPa}$ was measured. The water sorbed mass at equilibrium is expressed as a function of temperature on fig. 7. As expected, the sorbed mass decreases when the temperature increases. The slope is steeper for the 
lowest temperatures and limited desorption can be expected by heating above $120^{\circ} \mathrm{C}$. In the energy storage density measurement presented before, the desorption temperature was chosen at $80^{\circ} \mathrm{C}$, this temperature is easily reachable with glazed flat plate solar collectors. However, the material is not fully desorbed at this temperature (see fig. 7). Increasing the desorption temperature can increase the cycle loading lift and thus the energy storage density. For example, desorbing the material at $120^{\circ} \mathrm{C}$ makes it possible to further desorb $\sim 0.05 \mathrm{~g}$ water per $\mathrm{g}$ of composite material, with an expected increase of the stored energy (see fig.7). The desorption temperature of $120^{\circ} \mathrm{C}$ can be reached with evacuated tube solar collectors, concentrated solar collectors, as well as can be derived from a low grade industrial waste heat. Some extrapolations can be made, in order to give an order of magnitude of the heat storage density for $30-120^{\circ} \mathrm{C}$ cycles. For $30-80^{\circ} \mathrm{C}$ cycles, the exchanged water mass at the first cycle is $\sim 0.28 \mathrm{~g} / \mathrm{g}$, and for $30-120^{\circ} \mathrm{C}$ cycles, it is $\sim 0.34 \mathrm{~g} / \mathrm{g}$. Assuming that the heat storage density is proportional to the cycling loading lift, one finds $\sim 285 \mathrm{kWh} / \mathrm{m}^{3}$ for $30-120^{\circ} \mathrm{C}$, showing the benefit of desorbing the material at higher temperature.

Concerning the adsorption temperature, $30^{\circ} \mathrm{C}$ was chosen previously as it is typical of the temperature range of residential space heating when using radiant floor or fan-radiator. Higher temperature may be required when sanitary hot water production is considered. Increasing the adsorption temperature will reduce the cycle loading lift.

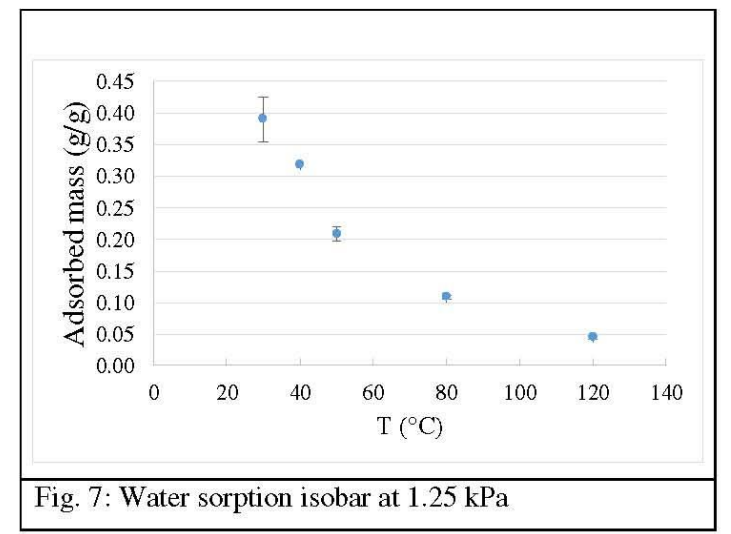

\section{CONCLUSIONS}

For the first time, strontium bromide has been successfully encapsulated in a mesoporous MOF (i.e., MIL$101(\mathrm{Cr})$ ) with a high salt content of $63 \mathrm{wt}$. \%. This salt is promising for residential heat storage applications and had never been encapsulated with such a high rate in a composite material.

This composite material obtained is a remarkable sorbent at low water partial pressure. The thermochemical analysis of these results and sorption isotherm show that the water sorption properties are enhanced in comparison to the pure $\mathrm{SrBr}_{2}$ or pure MOF. In the real conditions of the space heating application $(1.25 \mathrm{kPa}$, $30^{\circ} \mathrm{C}$ ), it adsorbs $0.4 \mathrm{~g}$ water $/ \mathrm{g}$ dry composite. Using solar collectors producing heat at $80^{\circ} \mathrm{C}$, a cycle loading lift of $0.303 \mathrm{~g} / \mathrm{g}$ was measured, leading to a heat storage density of $233 \mathrm{kWh} / \mathrm{m}^{3}$. The performance of this composite is thus comparable to that of the most promising composites reported in the literature so far. Moreover, this composite exhibits a good cycling performance.

In the experimental conditions, the salt was expected to exchange 5 molecules of water per unit $\mathrm{SrBr}_{2}$ During the experiments, $\sim 9$ molecules were exchanged, which partially explains the high energy storage density. Two assumptions were considered to explain the excellent heat storage properties. Firstly, the water sorption surplus may be due to enhanced physisorption by ML-101(Cr). Secondly, this surplus may be due to absorption by the salt, rather than chemisorption. Both assumptions cannot fully explain the high performance of this composite, the properties of which are driven by its complex microstructure. In particular, it may be expected that upon water sorption, the salt is partially soluble and randomly distributed in the porosity of $\mathrm{ML}-101(\mathrm{Cr})$. Moreover, upon the salt encapsulation, the hydrophilic character of $\mathrm{ML}$ $101(\mathrm{Cr})$ is significantly higher than the pure $\mathrm{ML}-101(\mathrm{Cr})$ and this may strongly impact its water sorption properties. This new material presents different and unexpected sorption properties compared to MOF and salt taken separately. These enhanced sorption properties improve the performance of the MOF and the salt for the heat storage applications. Additional studies are still needed to further clarify the sorption mechanism. 


\section{ACKNowledgement}

The authors acknowledge the European Commission for funding the SoTherCo project, under the $7^{\text {th }}$ Framework Programme (FP7)(grant agreement nr. 295775, website: http://www.sotherco.eu). They also acknowledge FEDER-Fonds social européen funding (www.enmieux.be, Wallonie, B) for the STOCC project and ULB for funding long-term missions of P. D'Ans at Versailles University.

\section{REFERENCES}

[1] Eurostat, , 2014 consulté en 2017, sur http://ec.europa.eu/eurostat/statisticsexplained/index.php/Electricity production, consumption and market overview/fr.

[2] N'Tsoukpoe, K., Liu, H., Pierrès, N. L. and Luo, L., "A review on long-term sorption solar energy storage", Renewable and Sustainable Energy Reviews 13 (2009) 2385-2396

[3] Permyakova, A., Wang, S., Courbon, E., Nouar, F., Heymans, N., D'Ans, P., Barrier, N., Billemont, P., Weireld, G. D., Steunou, N., Frère, M. and Serre, C., "Design of salt-metal organic framework composites for seasonal heat storage applications", Journal of Materials Chemistry A 5 (2017) 12889-12898.

[4] Aristov, Y., Tokarev, M., Cacciola, G. and Restuccia, G., "Selective water sorbents for multiple applications, $1 . \mathrm{CaCl}_{2}$ confined in mesopores of silica gel: Sorption properties", Reaction Kinetics and Catalysis Letters 59 (1996) 325-333.

[5] Mugnier, D. and Goetz, V., "Energy storage comparison of sorption systems for cooling and refrigeration", Solar Energy 71 (2001) 47-55.

[6] van Essen, V. M., Zondag, H. A., Cot Gores, J., Bleijendaal, L. P. J., Bakker, M., Schuitema, R., van Helden, W. G. J., He, Z. and Rindt, C. C. M., "Characterization of $\mathrm{MgSO}_{4}$ Hydrate for Thermochemical Seasonal Heat Storage", Journal of Solar Energy Engineering 131 (2009) 0410141-0410147.

[7] Lahmidi, H., Mauran, S. and Goetz, V., "Definition, test and simulation of a thermochemical storage process adapted to solar thermal systems", Solar Energy 80 (2006) 883-893.

[8] Mauran, S., Lahmidi, H. and Goetz, V., "Solar heating and cooling by a thermochemical process. First experiments of a prototype storing $60 \mathrm{~kW}$ h by a solid/gas reaction", Solar Energy 82 (2008) 623-636.

[9] Michel, B., Mazet, N., Mauran, S., Stitou, D. and Xu, J., "Thermochemical process for seasonal storage of solar energy: Characterization and modeling of a high density reactive bed", Energy 47 (2012) 553-563.

[10] Zhang, Y., Wang, R., Zhao, Y., Li, T., Riffat, S. and Wajid, N., "Development and thermochemical characterizations of vermiculite/ $\mathrm{SrBr}_{2}$ composites sorbents for lowtemperature heat storage", Energy 115 (2016) 120-128.

[11] Zhao, Y., Wang, R., Zhang, Y. and Yu, N., "Development of $\mathrm{SrBr}_{2}$ composite sorbents for a sorption thermal energy storage system to store low-temperature heat", Energy 115 (2016) 129-139.

[12] Cot-Gores, J., Castell, A. and Cabeza, L., "Thermochemical energy storage and conversion: A state-of-the-art review of the experimental research under practical conditions", Renewable and Sustainable Energy Reviews 16 (2012) 5207-5224.

[13] A. de Gracia and Cabeza, L., "Phase change materials and thermal energy storage for buildings", Energy and Buildings 103 (2015) 414-419.

[14] Dreos, A., Börjesson, K., Wang, Z., Roffey, A., Norwood, Z., Kushnir, D. and MothPoulsen, K., "Exploring the potential of a hybrid device combining solar water heating and molecular solar thermal energy storage", Energy \& Environmental Science 10 (2017) 728734.

[15] Cabeza, L., Solé, A. and Barreneche, C., "Review on sorption materials and technologies for heat pumps and thermal energy storage", Renewable Energy 110 (2017) 3-39. 
[16] Solé, A., Martorell, I. and Cabeza, L., "State of the art on gas-solid thermochemical energy storage systems and reactors for building applications", Renewable and Sustainable Energy Reviews 47 (2015) 386-398.

[17] N'Tsoukpoe, K., Schmidt, T., Rammelberg, H., Watts, B. and Ruck, W., "A systematic multi-step screening of numerous salt hydrates for low temperature thermochemical energy storage", Applied Energy 124 (2014) 1-16.

[18] Gilles, D., Segato, T., Courbon, E., Degrez, M. and D'Ans, P., "Affordable Process for the Production of Strontium Bromide used in Low Grade Heat Recovery Applications", Procedia CIRP 69 (2017) 383-388.

[19] Fopah-Lele, A. and Tamba, J., "A review on the use of $\mathrm{SrBr}_{2} \cdot 6 \mathrm{H}_{2} \mathrm{O}$ as a potential material for low temperature energy storage systems and building applications", Solar Energy \& Solar Cells 164 (2017) 175-187.

[20] D'Ans, P., Degrez, M., Frère, M. and Courbon, E. "Hygroscopic salt apparatus," Patent no. WO 2016/050912 A1.

[21] Courbon, E., D'Ans, P., Permyakova, A., Skrylnyk, O., Steunou, N., Degrez, M. and Frère, M., "A new composite sorbent based on $\mathrm{SrBr} 2$ and silica gel for solar energy storage application with high energy storage density and stability", Applied Energy 190 (2017) 1184-1194.

[22] Jaenchen, J., Ackermann, D., Stach, H. and Broesicke, W., "Studies of the water adsorption on zeolites and modified mesoporous materials for seasonal storage of solar heat", Solar Energy 76 (2004) 339-344.

[23] Stach, H., Mugele, J., Jaenchen, J. and Weiler, E., "Influence of Cycle Temperatures on the Thermochemical Heat Storage Densities in the Systems Water/Microporous and Water/Mesoporous Adsorbents", Adsorption 11 (2005) 393-404.

[24] Olives, R. and Mauran, S., "A Highly Conductive Porous Medium for Solid-Gas Reactions: Effect of the Dispersed Phase on the Thermal Tortuosity", Transport in Porous Media 43 (2001) 377-394.

[25] Canivet, J., Fateeva, A., Guo, Y., Coasne, B. and Farrusseng, D., "Water adsorption in MOFs: fundamentals and applications", Chemical Society Reviews 43 (2014) 5594-5617.

[26] Henninger, S., Habib, H. and Janiak, C., "MOFs as Adsorbents for Low Temperature Heating and Cooling Applications", Journal of the American Chemical Society 131 (2009) 2776-2777.

[27] Cadiau, A., Lee, J., Borges, D., Fabry, P., Devic, T., Wharmby, M., Martineau, C., Foucher, D., Taulelle, F., Jun, C., Hwang, Y., Stock, N., Lange, M. D., Kapteijn, F., Gascon, J., Maurin, G., Chang, J. and Serre, C., "Design of Hydrophilic Metal Organic Framework Water Adsorbents for Heat Reallocation", Advanced Materials 27 (2015) 4775-4780.

[28] Wang, S., Lee, J. S., Wahiduzzaman, M., Park, J., Muschi, M., Martineau-Corcos, C., Tissot, A., Cho, K. H., Marrot, J., Shepard, W., Maurin, G., Chang, J. S. and Serre, C., "A Robust Large-Pore Zirconium Carboxylate Metal-Organic Framework for Energy-Efficient and Water Sorption-Driven Refrigeration", Nature Energy 3 (2018) 985-993.

[29] Cui, S., Qin, M., Marandi, A., Steggles, V., Wang, S., Feng, X., Nouar, F. and Serre, C., "Metal-Organic Frameworks as advanced moisture sorbents for energy-efficient high temperature cooling", Scientific Reports 8 (2018) 15284

[30] Henninger, S., Ernst, S., Gordeeva, L., Bendix, P., Fröhlich, D., Grekova, A., Bonaccorsi, L., Aristov, Y. and Jaenchen, J., "New materials for adsorption heat transformation and storage", Renewable Energy 110 (2017) 59-68.

[31] Permyakova, A., Skrylnyk, O., Courbon, E., Affram, M., Wang, S., Lee, U., Valekar, A., Nouar, F., Mouchaham, G., Devic, T., Weireld, G. D., Chang, J., Steunou, N., Frère, M. and Serre, C., "Synthesis Optimization, Shaping, and Heat Reallocation Evaluation of the Hydrophilic Metal-Organic Framework MIL-160(Al)", ChemSusChem 10 (2017) 14191426. 
[32] Seo, Y.-K., Yoon, J., Lee, J., Hwang, Y., Jun, C., Chang, J., Wuttke, S., Bazin, P., Vimont, A., Daturi, M., Bourrelly, S., Llewellyn, P. L., Horcajada, P., Serre, C. and Férey, G., "Energy-Efficient Dehumidification over Hierachically Porous Metal-Organic Frameworks as Advanced Water Adsorbents", Advanced Materials 24 (2012) 806-810.

[33] Ehrenmann, J., Henninger, S. and Janiak, C., "Water Adsorption Characteristics of MIL-101 for Heat-Transformation Applications of MOFs", European Journal of Inorganic Chemistry 2011 (2011) 471-474.

[34] Thomann, F., Hall, M., Mokaya, R. and Stevens, L., "Hygrothermal simulation-informed design of mesoporous desiccants for optimised energy efficiency of mixed mode air conditioning systems", Journal of Materials Chemistry A 3 (2015) 17290-17303.

[35] Khutia, A., Rammelberg, H. U., Schmidt, T., Henninger, S. and Janiak, C., "Water Sorption Cycle Measurements on Functionalized MIL-101Cr for Heat Trabsformation Application", Chemistry of Materials 25 (2013) 790-798.

[36] Küsgens, P., Rose, M., Senkovska, I., Fröde, H., Henschel, A., Siegle, S. and Kaskel, S., "Characterization of metal-organic frameworks by water adsorpion", Microporous and Mesoporous Materials 120 (2009) 325-330.

[37] Ko, N., Choi, P., Hong, J., Yeo, M., Sung, S., Cordova, K., Park, H., Yang, J. and Kim, J., "Tailoring the water adsorption properties of MIL-101 metal-organic frameworks by partial functionalization", Journal of Materials Chemistry A 3 (2015) 2057-2064.

[38] Luan, Y., Yang, M., Ma, Q., Qi, Y., Gao, H., Wu, Z. and Wang, G., "Introduction of an organic acid phase changing material into metal-organic frameworks and the study of its thermal properties", Journal of Materials Chemistry A 4 (2016) 7641-7649.

[39] Garzón-Tovar, L., Pérez-Carvajal, J., Imaz, I. and Maspoch, D., "Composite Salt in Porous Metal-Organic Frameworks for Adsorption Heat Transformation", Advanced Functional Materials 27 (2017) 1606424.

[40] Férey, G., Mellot-Draznieks, C., Serre, C., Millange, F., Dutour, J., Surblé, S. and Margiolaki, I., "A Chromium Terephtalate-Based Solid with Unusually Large Pore Volumes and Surface Area", Science 309 (2005) 2040-2042.

[41] Yu, N., Wang, R. and Lu, Z., "Development and characterization of silica gel-LiCl composite sorbents for thermal energy storage", 111 (2014) 73-84.

[42] Courbon, E., D’Ans, P., Permyakova, A., Skrylnyk, O., Steunou, N., Degrez, M. and Frère, M., "Further improvement of the synthesis of silica gel and $\mathrm{CaCl}_{2}$ composites: Enhancement of energy storage density and stability over cycles for solar heat storage coupled with space heating applications", Solar Energy 157 (2017) 532-541.

[43] Wagman, D., Evans, W., Parker, V., Schumm, R., Halow, I., Bailey, S., Churney, K. and Nuttal, R., "The NBS tables of chemical thermodynamic properties." Journal of Physical and Chemical Reference Data 11 (1982) Supplement no. 2.

[44] Wu, H., Wang, S. and Zhu, D., "Effects of impregnating variables on dynamic sorption characteristics and storage properties of composite sorbent for solar heat storage", Solar Energy 81 (2007) 864-871.

[45] Grekova, A., Gordeeva, L. and Aristov, Y., "Composite "LiCl/vermiculite" as advanced water sorbent for thermal energy storage", Applied Thermal Engineering 124 (2017) 14011408 .

[46] Grekova, A., Gordeeva, L. and Aristov, Y., "Composite sorbents "Li/Ca halogenides inside Multi-wall Carbon Nano-tubes" for Thermal Energy Storage", Solar Energy Materials \& Solar Cells 155 (2016) 176-183. 